up and those who did not. Unadjusted analysis showed a strong association between CV mortality and E' ( $\mathrm{HR}=0.74, \mathrm{p}$ $<0.005)$ and $\mathrm{E} / \mathrm{E}^{\prime}(\mathrm{HR}=1.18, \mathrm{p}<0.005)$ (table 1$)$. The association between CV mortality and E' was attenuated slightly but persisted after adjusting for age and sex $(\mathrm{HR}=0.83, \mathrm{p}=$ $0.02)$ and after adjusting for age, sex and systolic BP $(\mathrm{HR}=$ $0.83, \mathrm{p}=0.03)$. The association between CV mortality and E/ E' was attenuated but persisted after adjusting for age and sex $(\mathrm{HR}=1.12, \mathrm{p}=0.01)$ and after adjusting for age, sex and systolic BP $(\mathrm{HR}=1.11, \mathrm{p}=0.04)$. There was a weak association between all-cause mortality and both $\mathrm{E} / \mathrm{E}$ ' and E', which was null after adjusting for age and sex. Figure 1 shows unadjusted Kaplan Meier survival curves for E'.

Conclusions Tissue Doppler E' velocity and E/E' are simple echocardiographic indicators of diastolic function and predicted 19-year cardiovascular mortality in a hypertensive population independent of age, sex and systolic blood pressure.

Conflict of Interest None

\section{LOW-GRADE HYPERTENSION AND CORONARY ATHEROSCLEROSIS IN MALE MASTER ENDURANCE ATHLETES}

${ }^{1}$ Gemma Parry-Williams, ${ }^{2}$ Daniel Obaid, ${ }^{3}$ Joanna Moser, ${ }^{4}$ Ioannis Vlahos, ${ }^{3}$ Paulo Bulleros, ${ }^{3}$ Zephryn Fanton, ${ }^{5}$ Joyee Basu, ${ }^{1}$ Christopher Miles, ${ }^{1}$ Hamish MacLachlan, ${ }^{6}$ Max MoreiraAccame, ${ }^{7}$ Athanasios Bakalakos, ${ }^{1}$ Idura Binti Ikmal Hisham, ${ }^{1}$ Irina Chis-Ster, ${ }^{8}$ Jamie O'Driscoll, ${ }^{1}$ Michael Papadakis, ${ }^{1}$ Maria Therese Tome Esteban, ${ }^{1}$ Sanjay Sharma. ${ }^{1}$ St George's University of London, London, UK; ${ }^{2}$ Swansea University Medical School, Swansea, Wales; ${ }^{3}$ St George's Hospital, London; ${ }^{4}$ MD Anderson Cancer Center, Houston, Texas; ${ }^{5}$ Royal Berkshire Hospital; ${ }^{6}$ Hospital San Juan de Dios, Costa Rica; ${ }^{7}$ St Bartholomew's Hospital, London; ${ }^{8}$ Canterbury Christ Church University

\subsection{6/heartjn--2021-BCS.180}

Background Ostensibly healthy male master endurance athletes have a greater prevalence of high coronary calcium (CAC) scores and coronary artery plaque burden, compared to similar aged, healthy sedentary counterparts. A number of theories have been postulated but reasons remain unclear. Hypertension is the leading cardiovascular risk factor in the general population. The role of subclinical hypertension and the hypertensive response to exercise (HRE) in the pathophysiology of high CAC scores and other CT markers of high-risk coronary artery disease, has not previously been reported in the healthy master endurance athlete population.

Methods A cohort of 214 low Q-risk, male master (40-65 years) endurance athletes were prospectively evaluated between February 2018 and September 2019. All athletes were free from any cardiovascular risk factors, symptoms and any relevant health conditions. Clinical evaluation included cycle ergometer cardiopulmonary exercise test, ambulatory BP monitoring and coronary computed tomogram angiography (CCTA). The CCTA assessed CAC score, coronary stenosis, defined as $>50 \%$, plaque morphology (i.e. calcified, soft or mixed), and markers of plaque vulnerability including spotty calcification, ruptured plaque, positive remodelling, low attenuation plaque and napkin ring sign. Resting BP, HRE and ambulatory hypertension were defined in accordance with the latest European Society of Cardiology (ESC) guidelines and are detailed in table 1.

Results All athletes (mean age 51, SD 70.1) exercised for at least 6 hours per week (median 8.5 hours) for a median of 15 years of either cycling, running or swimming or any combination of the three. The median $\mathrm{Q}$ risk score was 3.5\%. A quarter $(26 \%)$ of athletes were hypertensive at rest. A significant proportion of athletes exhibited exercise $(12 \%)$ and ambulatory hypertension (41\%). A CAC score $>100$ Agatston units (AU) was present in (16\%) of athletes, with $5 \%$ exhibiting significant coronary stenosis. A third (32\%) of all plaque morphologies were non-calcified ( $27 \%$ mixed and $5 \%$ soft) and $13 \%$ had additional plaque vulnerability markers. The most prevalent marker was spotty calcification (11.3\%), followed by positive remodelling (8.9\%). Logistic regression identified the BP parameters predictive for a CAC score $>100$ AU, significant stenosis and plaque vulnerability markers. A 5 $\mathrm{mmHg}$ increase in resting systolic BP, maximal systolic exercise $\mathrm{BP}$ and 24 hour and nocturnal ambulatory systolic were associated with both significant stenosis and plaque vulnerability markers and a $5 \mathrm{mmHg}$ increase in resting systolic BP (SBP) and 24 hour and nocturnal ambulatory SBP were associated with a CAC score $>100$ AU. The $\mathrm{p}$ values, odds ratios (OR) and respective $95 \%$ confidence intervals are detailed in table 3. BP parameters were not associated with calcified plaque by multinomial logistic regression, however for every $5 \mathrm{mmHg}$ increase in maximal exercise SBP, resting SBP and 24-hour and nocturnal ambulatory SBP, the relative risk (RR) of mixed morphology plaque was increased by $19.27 \% \quad(p=0.001$, CI

\begin{tabular}{|c|c|c|c|}
\hline \multirow{3}{*}{$\begin{array}{l}\text { Resting } \\
\text { Blood } \\
\text { Pressure }\end{array}$} & \multirow[t]{3}{*}{ Systolic (mmHg) } & & \multirow[t]{3}{*}{ Diastolic $(\mathrm{mmHg}$} \\
\hline & & & \\
\hline & & & \\
\hline High & $130-139$ & and/or & 85-89 \\
\hline \multicolumn{4}{|l|}{ Normal } \\
\hline & Hypertension & $\geq 140$ & and/or \\
\hline \multicolumn{4}{|l|}{$\geq 90$} \\
\hline - Grade 1 & $140-159$ & and/or & $90-99$ \\
\hline - Grade 2 & $160-179$ & and/or & $100-109$ \\
\hline \multirow[t]{7}{*}{ - Grade 3} & $\geq 180$ & and/or & $\geq 110$ \\
\hline & Ambulatory & & \\
\hline & Hypertension & & \\
\hline & (any of & & \\
\hline & following on & & \\
\hline & 24hour & & \\
\hline & monitoring) & & \\
\hline - 24 hour & $\geq 130$ & and/or & $\geq 80$ \\
\hline \multicolumn{4}{|l|}{ or } \\
\hline - Diurnal & $\geq 140$ & and/or & $\geq 90$ \\
\hline \multicolumn{4}{|l|}{ or } \\
\hline - Nocturnal & $\geq 120$ & and/or & $\geq 70$ \\
\hline HRE & $\geq 220$ & & \\
\hline
\end{tabular}

Abstract 183 Table 2 Prevalence of hypertension according to ESC guideline classifications

\begin{tabular}{ll}
\hline Grade of hypertension & Resting Hypertension \\
\hline Total Abnormal i.e. $\geq 130 / 85 \mathrm{mmHg}(\%)$ & $115(53.74)$ \\
Total Hypertensive (\%) & $55(25.71)$ \\
High Normal (\%) & $60(28.04)$ \\
Grade $1(\%)$ & $44(20.56)$ \\
Grade 2 (\%) & $10(4.67)$ \\
Grade 3 (\%) & $1(0.47)$ \\
\hline
\end{tabular}


Abstract 183 Table 3 Logistic regression $P$ values, odd ratios and confidence intervals for a $5 \mathrm{mmHg}$ increase in BP parameters

\begin{tabular}{|c|c|c|c|c|c|c|c|c|}
\hline & \multicolumn{2}{|c|}{$\begin{array}{l}\text { Maximum } \\
\text { exercise } \\
\text { systolic BP } \\
(5 \mathrm{mmHg})\end{array}$} & \multicolumn{2}{|c|}{$\begin{array}{l}\text { Resting } \\
\text { systolic BP } \\
(5 \mathrm{mmHg})\end{array}$} & \multicolumn{2}{|c|}{$\begin{array}{l}24 \text { Hours } \\
\text { ambulatory BP } \\
(5 \mathrm{mmHg})\end{array}$} & \multicolumn{2}{|c|}{$\begin{array}{l}\text { Nocturnal } \\
\text { Ambulatory BP } \\
(5 \mathrm{mmHg})\end{array}$} \\
\hline & $\begin{array}{l}\text { OR } \\
(95 \% \\
\text { Cl) }\end{array}$ & $\begin{array}{l}P \\
\text { value }\end{array}$ & $\begin{array}{l}\text { OR } \\
(95 \% \\
\text { Cl) }\end{array}$ & $\begin{array}{l}\mathrm{P} \\
\text { value }\end{array}$ & $\begin{array}{l}\text { OR } \\
(95 \% \\
\text { CI) }\end{array}$ & $\begin{array}{l}P \\
\text { value }\end{array}$ & $\begin{array}{l}\text { OR } \\
(95 \% \\
\mathrm{Cl})\end{array}$ & $\begin{array}{l}P \\
\text { value }\end{array}$ \\
\hline $\begin{array}{l}\text { CAC Score } \\
>100 \mathrm{AU}\end{array}$ & N/A & 0.498 & $\begin{array}{l}1.21 \\
(1.07- \\
1.37)\end{array}$ & 0.003 & $\begin{array}{l}1.23 \\
(0.99- \\
1.54)\end{array}$ & 0.06 & $\begin{array}{l}1.28 \\
(1.05- \\
1.57)\end{array}$ & 0.016 \\
\hline Stenosis $>50 \%$ & $\begin{array}{l}1.26 \\
(1.09- \\
1.46)\end{array}$ & 0.002 & $\begin{array}{l}1.31 \\
(1.09- \\
1.58)\end{array}$ & 0.005 & $\begin{array}{l}1.74 \\
(1.24- \\
2.46)\end{array}$ & 0.002 & $\begin{array}{l}1.50 \\
(1.10- \\
2.03)\end{array}$ & 0.01 \\
\hline $\begin{array}{l}\text { Plaque } \\
\text { Vulnerability } \\
\text { Markers }\end{array}$ & $\begin{array}{l}1.14 \\
(1.04- \\
1.25)\end{array}$ & 0.004 & $\begin{array}{l}1.16 \\
(1.02- \\
1.32)\end{array}$ & 0.022 & $\begin{array}{l}1.36 \\
(1.07- \\
1.71)\end{array}$ & 0.01 & $\begin{array}{l}1.43 \\
(1.15- \\
1.78)\end{array}$ & 0.001 \\
\hline
\end{tabular}

1.07-1.33), $18.49 \% \quad(\mathrm{p}=0.024, \quad$ CI $1.02-1.37), \quad 46.45 \%$ $(\mathrm{p}=0.001$, CI $1.12-1.91)$ and $50.54 \% \quad(\mathrm{p}=0.001$, CI 1.18 1.93) respectively.

Conclusions Hypertension is prevalent, under diagnosed, and contributes to the development of potentially unstable coronary artery disease in healthy male endurance athletes. Recommendations for cardiovascular evaluation of master athletes should consider a low threshold for non-invasive exercise testing and ambulatory BP monitoring for for athletes with hypertension and even high-normal BP. Table 1. ESC definitions of hypertension. Table 2. Prevalence of hypertension according to ESC guideline classifications. Table 3. Logistic regression P values, odds ratios and confidence intervals for a $5 \mathrm{mmHg}$ increase in BP parameters.

Conflict of Interest Nil

\section{ASSOCIATION BETWEEN HIGH-SENSITIVITY TROPONIN AND ONE YEAR MORTALITY IN 20,000 CONSECUTIVE HOSPITAL PATIENTS UNDERGOING A BLOOD TEST FOR ANY REASON}

${ }^{1} J o n a t h a n$ Hinton, 'Mark Mariathas, 'Lavinia Gabara, ${ }^{1}$ Rick Allan, 'Zoe Nicholas, ${ }^{2}$ Chun Shing Kwok, 'Sanjay Ramamoorthy, 'Alison Calver, 'Simon Corbett, 'John Rawlins, ${ }^{1}$ lain Simpson, ${ }^{1}$ James Wilkinson, ${ }^{1}$ Rohit Sirohi, ${ }^{1}$ Michael Mahmoudi, ${ }^{3}$ Glen Martin, ${ }^{1}$ Paul Cook, ${ }^{2}$ Mamas Mamas, ${ }^{4}$ Nick Curzen. 'University Hospital Southampton, Southampton, UK; ${ }^{2}$ University of Keele; ${ }^{3}$ University of Manchester; ${ }^{4}$ University of Southampton

\subsection{6/heartjnl-2021-BCS.181}

Introduction High sensitivity troponin (hs-cTn) concentrations above the manufacturer recommended upper limit of normal (ULN) are seen frequently in patients without a clinical presentation consistent with an acute coronary syndrome. There is increasing evidence that these concentrations may act as a marker of prognosis in a range of conditions. However, previous studies have been limited because they have only included patients in whom the clinician has requested the test. The aim of this study was to assess the relationship between one year mortality and hs-cTn concentration in a consecutive hospital population, regardless of whether there was a clinical indication for performing the test.

Method This study included 20,000 consecutive patients that had hs-cTnI added onto their blood tests at a large teaching hospital, regardless of the clinical indication (CHARIOT population). One year mortality data was obtained by linkage with NHS Digital. The association between hs-cTnI concentration and one year mortality was evaluated using Kaplan-Meier plots and Cox proportional hazards analyses. After the cohort was considered as a whole, each of the clinical areas (inpatient (IPD), outpatient (OPD), emergency department (ED)) were considered separately.

Results Overall, 1782 (8.9\%) patients had died at one year. Multivariable Cox regression analysis showed that a hs-cTnI concentration above the ULN was independently associated

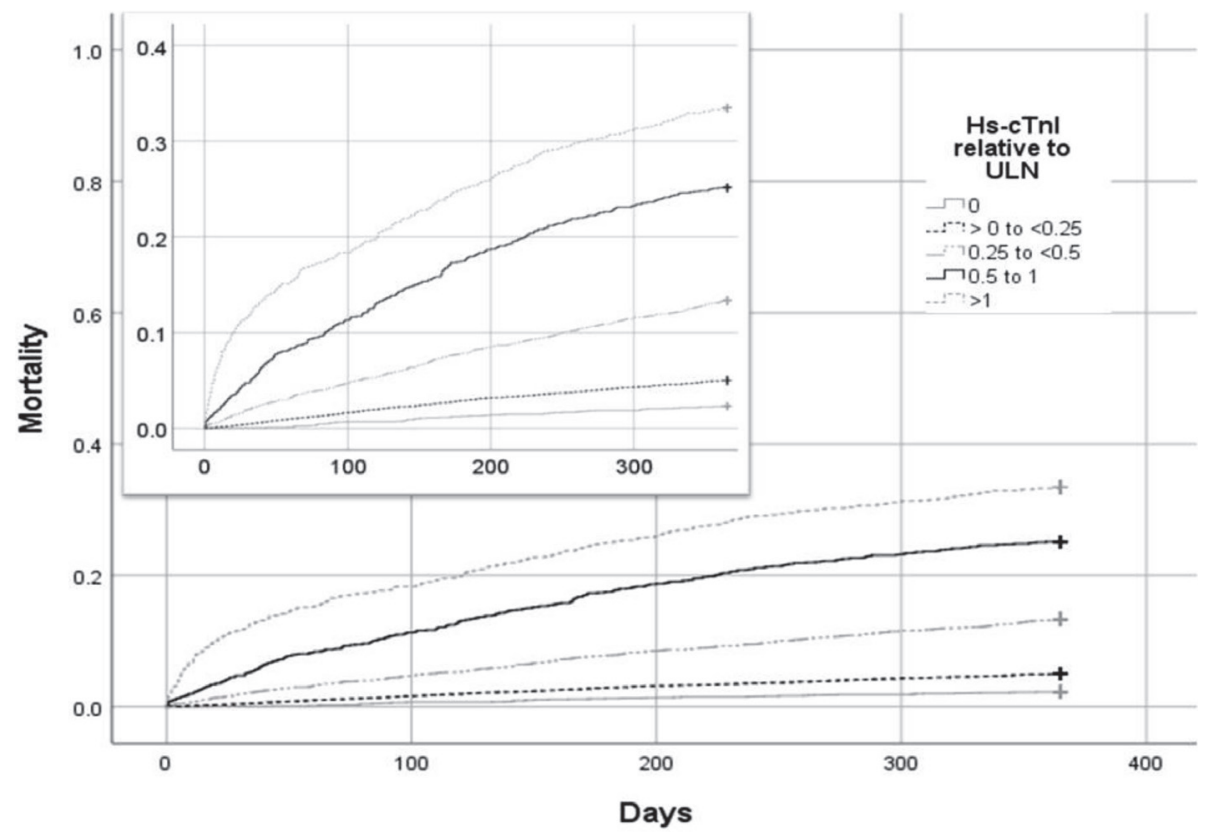

Abstract 184 Figure 1 Kaplan-Meier curve of one year mortality based on the ratio of the hs-cTnl concentration to the ULN (log rank test between each stratum $\mathrm{p}<0.001$ ) 